\title{
Assessment of diversity among trifoliate citrus accessions based on floral traits
}

\author{
Kuldeep Singh Bhullar* and Harinder Singh Rattanpal \\ Department of Fruit Science, Punjab Agricultural University, Ludhiana (Punjab) India \\ (Email: ksbhullar@pau.edu)
}

\begin{abstract}
The study was planned to assess genetic diversity among citrus trifoliate rootstocks. Sixteen Citrus trifoliate (Poncirus trifoliate and its hybrids) rootstocks were evaluated for different characters as per IPGRI citrus descriptors. Genotypes were significantly different for start of flowering, full bloom and end of flowering. Swingle was earliest to flower $21^{\text {st }}$ February followed by X-639 $\left(2^{\text {nd }}\right.$ March $)$ and flying dragon $\left(15^{\text {th }}\right.$ March $)$ was the last to start flowering. Significant variation for all the quantitative flower traits was recorded. The highest mean flower diameter of $51.38 \mathrm{~mm}$ was recorded in U-852 and the lowest in flying dragon $(20.14 \mathrm{~mm})$. Flower length was highest in C-32 $(25.59 \mathrm{~mm})$ followed by U-852 $(23.39 \mathrm{~mm})$ and the lowest mean flower length was recorded in chethali trifoliate $(8.60 \mathrm{~mm})$. C-32 exhibited highest pedicel diameter of $2.14 \mathrm{~mm}$ and the lowest was observed in swingle citrumelo $(1.37 \mathrm{~mm})$. Pedicel length was in the range of 0.00-9.81 $\mathrm{mm}$. Longer mean petal length of $27.04 \mathrm{~mm}$ was observed in C-32. The highest stamen number of 29.50 was observed in C-32 which was statistically at par with carrizo (27.80) and the lowest number of 13.41 was observed in rubidoux. The dendrogram based on un-weighted pair group method with arithmetic mean (UPGMA) divided all the sixteen genotypes into six clusters (Group I, II, III, IV, V and VI).
\end{abstract}

Key Words : UPGMA,Citrus, Trifoliate, Rootstock, Characterization

View Point Article : Bhullar, Kuldeep Singh and Rattanpal, Harinder Singh (2020). Assessment of diversity among trifoliate citrus accessions based on floral traits. Internat. J. agric. Sci., 16 (1) : 73-78, DOI:10.15740/HAS/IJAS/16.1/73-78. Copyright@ 2020: Hind AgriHorticultural Society.

Article History : Received : 21.10.2019; Revised : 14.11.2019; Accepted : 17.12.2019

* Author for correspondence: 